\title{
The role of elective courses in higher medical education during pre-clinical years
}

\author{
M. Y. Shumylo \\ Lviv Polytechnic National University \\ Corresponding author. E-mail: mirra.leopolis@gmail.com \\ Paper received 05.11.19; Accepted for publication 19.11.19.
}

https://doi.org/10.31174/SEND-PP2019-209VII86-10

\begin{abstract}
The leading aim of medical education is to develop an individual's ability of creative and critical reasoning, to comprehend new experience based on the methods of educational and research activity. Requirements in medical education, curriculum structure, criteria, teaching methodology, and nature of programs vary worldwide. However, curricula are usually divided into compulsory and elective pre-clinical and clinical subjects. Electives can contribute to professional and personal development of medical students in specific areas of interest outside of the standard curriculum. Elective courses can be referred to two main types: subject-oriented, which enable students to develop their own cognitive interests in the chosen area, get profound knowledge in the sphere of interest as well as to form skills for important practical tasks; interdisciplinary, the aim of which is to take knowledge and methods of one discipline and apply them in another one to provide more profound learning experience and broader perspectives. On the other hand, electives are thought to be less regulated and monitored than compulsory disciplines, thus having less benefit for students.
\end{abstract}

Keywords: electives, medical student, pre-clinical subjects, curriculum, medical establishment.

Introduction. Progressive changes occurring in the world in the recent years promote appearance of new demands for the quality of professional education. They can be implemented under conditions of improvements in education. The aim of higher educational establishments is to train specialists, who are capable to think systemically, make reasonable judgments, apply creative imagination, and know how to achieve goals. The primary attention should be focused not on extent, but fundamentality of teaching, knowledge of the leading concepts in advancements of science and technologies, and formation of self-education skills. Among American educators, ideas of development of students' creative potential through cognition of social experience and involvement are common. Thus, the leading aim of education is to develop an individual's ability of creative and critical reasoning, to comprehend new experience based on the methods of educational and research activity. The notion "quality" in education defines aspects of educational processes, impact on students' educational abilities, conditions of training. The notion "standards" refers to expected and real levels of education results.

Throughout the world, requirements in medical education, curriculum structure, criteria, teaching methodology, and nature of programs vary. However, entrance to medical establishments is highly competitive and requires taking standardized entrance exams. Curricula in medical education are usually divided into pre-clinical and clinical subjects, with certain subjects being compulsory and some elective. The latter means a course that a student can select from among the alternatives.

Review of publications. The term "elective" usually implies presence of the subjects in the curriculum, which enable students to choose. The challenges of realizing educational benefits from an elective have resulted in many questioning whether the elective still has a role in undergraduate training [6, 11]. However, they remain among components of undergraduate medical education, with benefits for a student resulting in extension of skills via personal development. The researchers [6] state that "this reminds medical education of the importance of flexibility within the type of electives included as curricular components within most undergraduate medical programs. Electives can contribute to both the professional and personal development of medical students in specific areas of interest outside of the standard curriculum [19].

However, some authors say that electives are comparatively less regulated and monitored than compulsory disciplines, thus having less benefit for students. In many medical schools they remain largely untouched by significant educational innovations and practice seen in the approach to other curricular elements over the last two decades and their potential contribution to learning, not only within global health, thus underutilized [3]. The elective may be the least-researched component of a medical course [11].

There is a wide range of activities available to learners, and this provides a unique opportunity for students to challenge themselves personally, often beyond the premises of their home medical school. Ensuring a student-centered approach to elective organization requires schools to dedicate adequate resources to support not only the student's organization of a safe and educational elective, but as importantly to ensure maximizing educational, personal and professional development. Some standardization is important to optimize benefits for students, their education, and for both host and home medical school, and reduce diversity in placement quality [1]. Resources, poor organization and planning, and limited faculty expertise to support and guide students during electives have the potential to affect the quality of the experience and safety of the student [10].

Materials and methods. Literature review has been conducted to analyze articles referring to preclinical medical electives in the USA and Ukraine; the curricula of two American and Ukrainian universities have been studied.

The aim of the paper is to analyze the role of elective courses in medical university curricula, to compare the choice of subjects in American and Ukrainian universities and to focus on the advantages of electives.

Results and their discussion. Elective courses form a substantial part of medical curriculum worldwide, providing many benefits for medical students. The aim of 
electives is to orient students at individualization of learning and socialization, conscious and responsible choice of subjects that will contribute to future profession. The basic tasks of elective courses are creation of positive motivation to master a chosen subject, activation of students' cognitive activity, improvement of students' informative and communicative competency, etc. Electives perform the following functions:

- develop and extend the content of one of the compulsory subjects, mastering of which is accomplished at minimal fundamental level, which will help students get more profound knowledge in the interested subject;

- $\quad$ satisfy students' cognitive interests in different areas of activity, thus broadening students' general competence, ability to make individual decisions in complex situations;

Thus, elective courses can be referred to two main types: subject-oriented, which enable students to develop their own cognitive interests in the chosen area, get profound knowledge in the sphere of interest as well as to form skills for important practical tasks (research activity, practical training, future profession); interdisciplinary, the aim of which is to take knowledge and methods of one discipline and apply them in another one to provide more profound learning experience and broader perspectives.

Analyzing the curriculum of Danylo Halytsky Lviv National Medical University in pre-clinical years, we can see that the following subjects are offered for students' choice: Foreign language; Fundamentals of patenting; Historical disciplines in medical education; Cytophysiology; Contemporary problems of virology; Scientific speech of doctors; Outstanding figures in Ukrainian medicine; Information studies and statistics; Health of the nation; Law science; Logic, formal logic; Deontology in medicine; European standard of computer skills; First medical aid; Information technologies in medicine; Ethical problems in medicine; Clinical biochemistry; Sociology and medical sociology; Psychology of communication; Theory and practice of professional communication; History of medicine and pharmacy; Contemporary issues of molecular biology; Contemporary issues of biophysics, etc. It should be emphasized that medical students in Ukraine have a fixed choice of electives for each year. Thus, for, example, during the first year of study they can select a certain number of disciplines offered only for the given year.

A list of medical electives in the first and second years of study in the USA is taken from the curriculum of Brown Alpert Medical School [20]. The following choice of disciplines is offered: Race, health and structural inequality; Integrative medicine: From alternative to mainstream; Medical Chinese (Spanish, Portuguese, Arabic); Poverty, health and law; Healthcare in America; Introduction to fetal medicine; Science and power: a bioethical inquiry; Elective in mindfulness training; Gender and sexuality in healthcare: caring for all patients; Introduction to surgical subspecialties; Topics in medicine - an international perspective at university of Rostock, Germany; Comparative medical ethics at University of Tubeingen, Germany; Modern genetics: ethics, policy and the doctor-patient relationship; Playwriting in medicine; Diseases, doctors, and divas: opera and medicine; Design and health; Teamwork in the health professions; The healer's art; Religious literacy in medicine; Introduction to sports medicine; Art as a source of healing; Addiction medicine; Clinical applications of integrative and traditional Chinese medicine; The bionic human elective; Refugee health and advocacy; Medical impact of translational and basic science; Food and health; Business in medicine; Digital health; History of medicine; Medical journalism; Introduction to interventional radiology (Urology, Electronic health record, Multidisciplinary fetal medicine); Medicine in film and television, Studio art for medical practitioners, Spirituality in healthcare, etc.

As we can infer from the choices offered at two universities, American curriculum has a wider range of disciplines for elective courses. Besides, many of them are related to art and humanities. It has been a disputable issue whether humanities are necessary for future doctors. Humanities are important in medical education as they help students develop empathy and critical thinking, help build better doctor-patient, doctor-patients' families relationships, teamwork and other aspects of healthcare. Evans defined medical humanities as "an integrated, interdisciplinary, philosophical approach to recording and interpreting human experiences of illness, disability, and medical intervention" [7]. Doctors should have the understanding and knowledge of how the body works and thus be able to choose the best treatment for patients. However, individual patient's needs should also be considered. A medical professional must be able to apply scientific knowledge and skills for a particular patient, especially the individuals with mental problems, find approach in each clinical situation and make decisions. The clinician has to develop the ability to observe and recognize visual clinical signs of disease in the patient. This ability can be directly enhanced by the study of the visual arts [14]. Humanities and medical ethics provide students with skills of reasoning, judgment and insight essential to professionalism. Thus, medical ethics and humanities develop skills in narration and writing, textual reading, visual observation and interpretation. Such skills may also be helpful in interpreting the results of physical examination. Literature teaches that in any given situation there are multiple perspectives, making suspect the privileging of anyone's perspective (e.g., the physician's versus that of the patient or family), thereby helping to encourage humanism in physicians by eliciting and seeking to understand both the physician's and the patient's stories. Given that most diagnoses can be made based on a thorough history alone, the skills of eliciting and interpreting patients' stories are crucial for the preparation of medical professionals and the provision of proper health care. The use of literature in medicine courses is also largely elective [5].

In higher medical education, humanities help develop humanistic competence, reflexive reasoning, and analytical abilities. Humanities give medical students ability to build a doctor-patient relationship, to foster tolerance, to make judgments, to cultivate empathy, to acquire critical views in complex situations. Students should develop such abilities as listening, acknowledgement and interpretation of information, while dealing with future patients. Humanities improve medical students' reflexive skills and selfawareness as well as enhance interdisciplinary understanding. Teaching ethics, art and medical humanities 
plays a vital role in objective assessment of the goals pursued in medicine, the ways of improving doctor-patient relationship and connection of medical professionals with the society. Medical ethics and humanities allow teaching medical students to think critically, being involved in an objective assessment of medical professionalism.

Students at Ukrainian medical universities take electives at home universities, only a small percentage of learners participate in some exchange programs, since this issue has not been developed fully in Ukrainian universities. On the contrary, a considerable proportion of elective courses in the USA can be undertaken in different geographical and cultural settings. Moreover, for American students, electives are also an opportunity to gain practical experience outside their university and country, which can be beneficial for learners as they acquire new cultural and clinical skills, as well as gain additional experience.

Thus, electives can be broadly classified into the following five categories:

Global health. Getting acquainted with healthcare in a different cultural and geographical setting is one of the most common types of electives. Learners go abroad to face a different range of diseases and pathologies, to broaden their clinical skills and gain practical experience. Valuable experience may also be acquired in international public health, and the World Health Organization supports many elective placements for students. Besides, an international elective in health care may involve encounter with models of healthcare management different from the students' training environment. Students who travel to countries with no state-provided healthcare are thus challenged to consider advantages and disadvantages of health care systems and access to such facilities in their home country. Understanding different healthcare systems and learning to manage diseases not normally seen at home are the most common educational objectives for this type of elective [4]. Benefits of global health experiences contribute to cultural competence. Both students and educational establishments will benefit from awareness of global health problems and issues. Collaborations and initiatives have advantages for the society, involving public and patients within the issues of the medical institutions, and foster growth and development of educational establishments.

Project work. Electives last several weeks and thus give opportunity to be involved in a formal project. There are various project types ranging from engagement in contemporary laboratory-based investigation to exposure to clinical practice. Many learners may utilize their elective courses to conduct research, as this may provide additional time to complete a project that was commenced in their home medical school, for example, a laboratory-based project that requires more time for completion than allowed within allocated time. Preparatory work can be initiated that includes relevant literature or documentary review, project planning and the development of project materials such as questionnaires. Project work within the elective thus provides an opportunity for students to undertake work of benefit to the host institution, and potentially engage in capacity building with a possibility for longer sustainable relationships, with either the student or the medical school [17].
Career choice. A popular motivation behind the choice of an elective placement is often to clarify the focus of a potential future career path [12]. The elective may be spent exploring a medical specialty the student may have already studied or gain experience in a specialty not covered in the compulsory curriculum. Students may opt for a career choice elective simply because they are interested in a particular specialty, although it is also possible that their motivation includes a strategy to enhance their chances of obtaining a better post-graduate post in a competitive market [12]. Career choice electives in non-clinical areas have also been purposively developed to market other aspects of medical careers to students, an example being the value of "research electives" in increasing the number of students considering an academic pathway for training [9].

Directed elective. Another important role electives can play in individual students' personal development is to support those who are struggling to undertake or required components of the course. Thus, students can be directed to use elective time to gain additional knowledge or skills in identified areas of their weaknesses. This may allow these students to resit failed course units and improve their competencies before graduation and thus avoid the need to prolong their studies. However, the role of the elective in this way may also be considered disadvantage for the weaker students by reducing their opportunities for selfdevelopment, including organizational skills.

Wellness elective. For some students the elective may be seen as an opportunity to have a change from required course components perceived to be more challenging. Some medical schools have taken this further and established specific "wellness" electives, aimed at helping students to cope with the stress of medical studies [8, 13]. Both of these "wellness" electives describe engagement of the students in specific developmental sessions around stress management. Feedback from students who volunteered for this intervention and the associated subsequent elective indicated long-term benefits, both in terms of developing coping mechanisms and an acceptance that engaging in such preparatory and potentially longer term "wellness" activities was appropriate. A wellness elective cannot be made mandatory for any particular student group, but one study did find that students who chose the wellness elective had higher anxiety scores than students who did not [8], indicating some success in targeting the group with most need. Furthermore, an elective designed in this way not only helps the individual student but also raises their awareness of health issues in the medical profession and potential ways of managing personal and professional problems [13].

Conclusion. Elective disciplines provide unique opportunities for medical students to design and organize individualized educational experiences. However, maximizing benefits from electives requires thoroughly defined and realistic training outcomes. Ethical issues should be a significant part of required professional elective practice. It can be stated that pre-clinical electives at medical educational establishments help develop:

- $\quad$ skills of thinking, analysis and reasoning;

- $\quad$ ability to learn and master up-to-date knowledge, to apply the knowledge in practical situations 
- $\quad$ extensive understanding of subject matter and professional activity;

- $\quad$ ability to adapt and act in new situation and make substantiated decisions;

- $\quad$ ability to work in a team, skills of interpersonal communication;

- $\quad$ ability to communicate in a foreign language professionally, to act conscientiously and responsibly towards society;
- $\quad$ skills of applying information and communication technologies in professional sphere for integration of knowledge;

- $\quad$ ability to collect necessary information, define its source and analyze the obtained information;

- ability to act according to ethical norms and principles.

\section{REFERENCES}

1. Anderson, K.C., Slatnik, M.A., Pereira, I., Cheung, E., Xu, K,, 11. Jolly, B. A missed opportunity. Med Educ., 2009. 43. P. 104Brewer, T. Global health education. Are we there yet? Preparing Canadian medical students for global health electives. Acad Med., 2012. 87. P. 206-209.

2. Balandin, S., Lincoln, M., Sen, R., Wilkins, D.P., Trembath, D. Twelve tips for effective international clinical placements. Med Teach, 2007. 29. P. 872-877.

3. Banerjee, A., Banatvala, N., Handa, A. Medical student electives: potential for global health? Lancet, 2011. 377(9765). P. 555.

4. Cherniak, W.A., Drain, P.K, Brewer, T.F. 2013. Educational objectives for international medical electives: a literature review. Acad Med., 2013. 88(11). P. 1778-1781. doi:10.1097/ACM.0b013e3182a6a7ce.

5. Doukas, David J., Laurence, B. McCullough, Wear, Stephen. Medical Education in Medical Ethics and Humanities as the Foundation for Developing Medical Professionalism. Academic Medicine, 2012. 87. P. 334-341.

6. Dowell, J., Merrylees, N. Electives: isn't it time for a change? Med Educ., 2009. 43. P 121-126.

7. Evans, M. Reflections on the humanities in medical education Medical Education, 2002. 36. P. 508-513.

8. Finkelstein, C., Brownstein, A., Scott, C., Lan, Y-L. Anxiety and stress reduction in medical education: an intervention. Med Educ., 2007. 41. P. 258-264.

9. Houlden, R.L., Raja, J.B., Collier, C.P., Clark, A.F., Waugh, J.M. Medical students' perceptions of an undergraduate research elective. Med Teach, 2004. 26. P. 659-661.

10. Jeffrey, J., Dumont, R.A., Kim, G.Y., Kuo, T. Effects of international health electives on medical student learning and career choice: Results of a systematic literature review. Fam Med, 2011. 43. P. 21-28. 